\title{
Long working hours and risk for hypertension in Japanese male white collar workers
}

\author{
N Nakanishi, H Yoshida, K Nagano, H Kawashimo, K Nakamura, K Tatara
}

\begin{abstract}
Study objective-To evaluate the association of long working hours with the risk for hypertension.
\end{abstract}

Design-A five year prospective cohort study.

Setting-Work site in Osaka, Japan.

Participants-941 hypertension free Japanese male white collar workers aged 35-54 years were prospectively examined by serial annual health examinations. Men in whom borderline hypertension and hypertension were found during repeated surveys were defined as incidental cases of borderline hypertension and hypertension.

Main results-336 and 88 men developed hypertension above the borderline level and definite hypertension during the $\mathbf{3 9 4 0}$ and 4531 person years, respectively. After controlling for potential predictors of hypertension, the relative risk for hypertension above the borderline level, compared with those who worked $<8.0$ hours per day, was 0.63 (95\% confidence intervals $(\mathrm{CI}): 0.43,0.91)$ for those who worked 10.0-10.9 hours per day and 0.48 (95\% CI: $0.31,0.74)$ for those who worked $\geqslant 11.0$ hours per day. The relative risk for definite hypertension, compared with those who worked $<8.0$ hours per day, was $0.33(95 \%$ CI: $0.11,0.95)$ for those who worked $\geqslant 11.0$ hours per day. The multivariate adjusted slopes of diastolic blood pressure (DBP) and mean arterial blood pressure (MABP) during five years of follow up decreased as working hours per day increased. From the multiple regression analyses, working hours per day remained as an independent negative factor for the slopes of systolic blood pressure, DBP, and MABP.

Conclusions-These results indicate that long working hours are negatively associated with the risk for hypertension in Japanese male white collar workers. (F Epidemiol Community Health 2001;55:316-322)

Japan Labour and Welfare Association, Tokyo, Japan

H Kawashimo

Medical Office, Osaka Main Office, Takenaka Corporation, Osaka,

Japan

K Nakamura

Correspondence to: Dr Nakanishi (noriyuki@ pbhel.med.osaka-u.ac.jp)

Accepted for publication 14 January 2001 much a part of the modern Japanese culture, is a major contributory factor for Karoshi resulting from hypertensive or arteriosclerotic disease.

As for the association between long working hours and blood pressure, the influence of long working hours on blood pressure is related to sympathetic nerve activity and concentrations of counterregulatory hormones that accompanies psychological stress ${ }^{12}{ }^{13}$ and physical activity. ${ }^{14}$ As overtime work is very often accompanied by such stress and physical activity, it is reasonable to expect an association between long working hours and the risk for hypertension. However, there is no convincing evidence to support the view that long working hours contribute to long term blood pressure and predisposition to hypertension. Therefore, it is necessary to conduct a longitudinal study to clarify the relation between long working hours and the risk for hypertension.

In this report on a longitudinal population study based on serial annual health examinations at the workplace, we have tried to prospectively examine the association between long working hours and the risk for hypertension in hypertension free Japanese male white collar workers.

\section{Methods}

STUDY COHORT

Our study is an ongoing cohort investigation designed to clarify risk factors for major diseases, including hypertension, dyslipidaemia, and diabetes among Japanese male white collar workers, not working in a shift system at $\mathrm{T}$ Corporation, one of the biggest building contractors in Osaka, Japan. The Industrial Safety and Health Law in Japan requires the employer to conduct annual health examinations of all employees; the employee data, which are anonymised, are available for research with the approval of the employer. To evaluate the association of long working hours with the risk for hypertension, a surveillance of the incidence of hypertension was conducted between 1994 and 1999. All Japanese male white collar workers 35-54 years of age in May 1994 were invited to take a survey $(n=1368)$; the participation rate was $99.9 \%(n=1367)$

Of 1367 potential participants, 257 (18.8\%) were identified to be borderline hypertensives, and $138(10.1 \%)$ to be hypertensives at the initial examination. For 23 men $(1.7 \%)$ who were taking medication for or had a past history of hypertension, normotensive blood pressure was registered. The remaining 949 men constituted the hypertension free cohort. We also excluded eight men who did not participate in 
consecutive annual health examinations during the follow up. The final study population for analysis therefore consisted of 941 men. Men in whom borderline hypertension and hypertension were found during repeated surveys through May 1999 were defined as incidental cases of borderline hypertension and hypertension. To determine the incidence of hypertension, incidental cases of borderline hypertension were followed up and were considered hypertension if this condition developed. Ten participants who started taking medication for hypertension during the observation period were considered to have incidental cases of hypertension.

\section{STUDY DESIGN}

Blood pressure was measured at annual health examinations in May from 1994 to 1999 . The participants were asked to fast for at least eight hours and to avoid smoking and heavy physical activity for more than two hours before the examinations. After a five minute rest in a quiet room, systolic blood pressure (SBP) and diastolic blood pressure (DBP) were measured on the right arm with a standard mercury sphygmomanometer, and mean arterial blood pressure (MABP) was calculated as DBP + (SBP-DBP)/3. Diagnosis of hypertension was based on World Health Organisation criteria. ${ }^{15}$ Hypertension was defined as SBP $\geqslant 160 \mathrm{~mm}$ $\mathrm{Hg}$ and/or $\mathrm{DBP} \geqslant 95 \mathrm{~mm} \mathrm{Hg}$ or receipt of antihypertensive medications, while normotension was defined as SBP $<140 \mathrm{~mm} \mathrm{Hg}$ and DBP $<90 \mathrm{~mm} \mathrm{Hg}$. Participants with blood pressures between these categories were defined as having borderline hypertension.

The health examinations included anthropometric measurements, a questionnaire on job and health related behaviours, and a nutritional survey. Height and weight were measured at every examination. Height in standing position (to the nearest $0.5 \mathrm{~cm}$ ) was measured and weight (to the nearest $0.5 \mathrm{~kg}$ ) was measured using a calibrated platform scale. Subjects were measured in light clothing and without shoes. Body mass index (BMI) was calculated as weight $/$ height $^{2}\left(\mathrm{~kg} / \mathrm{m}^{2}\right)$ and was used as the index for relative weight. As for job related variables, occupation and position were divided into two groups: occupation (clerks versus architects/research workers) and position (non-managers versus managers). Data on daily working hours and commutation hours were obtained by interview. Daily working hours for persons holding a managerial position were not recorded by means of time clocks in this company. Therefore, we used subjectively reported working hours in this study. The participants were asked about their normal daily activities, including rising time, company arrival and departure times, and turning in times. Hours of work per day were classified into five categories: $<8$ hours per day, $8.0-8.9$ hours per day, 9.0-9.9 hours per day, 10.010.9 hours per day, and $\geqslant 11$ hours per day. The company's regular work hours were eight hours per day ( 40 hours per week for five days per week). As for health related behaviors, the questions about alcohol intake included items about the type of alcoholic beverage, the frequency of alcohol consumption per week, and the usual amount consumed daily. Weekly alcohol intake was calculated and then converted to daily alcohol consumption (grams of ethanol per day) by using standard Japanese tables. The questionnaire asked about smoking habits (never, past, or current smoker); past or current smokers were asked about the number of cigarettes smoked per day and the duration of smoking in years. In this study, past and never smokers were combined, and the current amount of cigarettes smoked was used in the analysis. The questions also queried about eating breakfast, vegetable consumption, fruit consumption, regular physical exercise, and hours of sleep per night. As for the consumption of vegetables and fruits, the questionnaire asked about the number of servings of vegetables per day and fruits per week. Eating breakfast was divided into two groups: eating breakfast every morning versus not eating breakfast every morning. Vegetable consumption, fruit consumption, and regular physical exercise were categorised into three groups: vegetable consumption (eating vegetables hardly ever, eating vegetables once or twice per day, and eating vegetables three times per day); fruit consumption (eating fruits hardly ever, eating fruits three to six times per week, and eating fruits once or more per day); and regular physical exercise (exercising hardly ever, exercising once a week, and exercising twice or more per week). As for a nutrition survey, the participants were asked by trained interviewers to indicate the frequency of consumption and the average amount of food items, using a semiquantitative food frequency questionnaire. ${ }^{16}$ Salt intake (grams of sodium chloride per day) was calculated from each person's dietary record.

\section{STATISTICAL ANALYSIS}

The statistical differences of the characteristics at enrollment in relation to working hours were examined with the $\chi^{2}$ test and one way analysis of variance. For each subject, person years of follow up were counted from the date of enrollment to the date of diagnosis of borderline or definite hypertension or the date of follow up, whichever came first. The follow up rate was $99.3 \%$ of total potential person years of follow up. The Cox proportional hazards models ${ }^{17}$ were used to evaluate the association between working hours and the development of borderline or definite hypertension. Data were adjusted first for age alone, then for multiple covariates including age, occupation, position, MABP, BMI, alcohol intake, cigarette smoking, eating breakfast, vegetable consumption, regular physical activity, salt intake, hours of sleep, and hours of commutation at study entry. The linear trends in risks were evaluated by entering indicators for each category level of exposure, and men who worked $<8$ hours per day were used as a reference category. To represent a person's blood pressure trend during 1994 and 1999, each consecutive participant's six values of SBP, DBP, and MABP were regressed on the time of survey with a simple 
Table 1 Baseline characteristics of 941 hypertension free Fapanese male office workers, according to working hours per day

\begin{tabular}{|c|c|c|c|c|c|c|}
\hline \multirow[b]{2}{*}{ Characteristics } & \multicolumn{5}{|c|}{ Working hours per day } & \multirow[b]{2}{*}{$p$ value } \\
\hline & $\begin{array}{l}<8.0 \\
(n=256)\end{array}$ & $\begin{array}{l}8.0-8.9 \\
(n=240)\end{array}$ & $\begin{array}{l}9.0-9.9 \\
(n=165)\end{array}$ & $\begin{array}{l}10.0-10.9 \\
(n=146)\end{array}$ & $\begin{array}{l}\geqslant 11.0 \\
(n=134)\end{array}$ & \\
\hline Age (y) & $46.8(5.0)$ & $46.4(4.9)$ & $45.3(5.2)$ & $44.0(4.8)$ & $43.8(5.9)$ & $<0.001$ \\
\hline \multicolumn{7}{|l|}{ Occupation, \% } \\
\hline Architect/research worker & 51.2 & 66.3 & 60.0 & 70.5 & 71.6 & $<0.001$ \\
\hline \multicolumn{7}{|l|}{ Position, $\%$} \\
\hline Manager & 62.5 & 63.8 & 57.0 & 46.6 & 46.3 & $<0.001$ \\
\hline Systolic blood pressure (mm Hg) & $122.5(9.6)$ & $121.9(10.9)$ & $122.2(10.4)$ & $119.8(10.3)$ & $119.2(10.4)$ & 0.007 \\
\hline Diastolic blood pressure $(\mathrm{mm} \mathrm{Hg})$ & $73.0(7.9)$ & $72.7(8.6)$ & $73.8(8.3)$ & $72.1(8.8)$ & $71.4(8.5)$ & 0.122 \\
\hline Mean arterial blood pressure $(\mathrm{mm} \mathrm{Hg})$ & $89.5(7.5)$ & $89.1(8.4)$ & $90.0(8.2)$ & $88.0(8.5)$ & $87.4(8.4)$ & 0.026 \\
\hline Body mass index $\left(\mathrm{kg} / \mathrm{m}^{2}\right)$ & $23.2(2.6)$ & $22.9(2.5)$ & $23.4(2.5)$ & $22.7(2.3)$ & $22.9(2.6)$ & 0.038 \\
\hline Alcohol intake (g/day of ethanol) & $32.1(25.5)$ & $33.7(26.5)$ & $29.8(23.9)$ & $34.1(24.2)$ & $27.4(24.9)$ & 0.104 \\
\hline Smoking (cigarettes/day) & $16.2(17.0)$ & $14.9(17.2)$ & $13.3(16.4)$ & $13.4(16.3)$ & $17.3(18.0)$ & 0.156 \\
\hline \multicolumn{7}{|l|}{ Eating breakfast, \% } \\
\hline Not every morning & 15.2 & 15.4 & 11.5 & 13.0 & 19.4 & 0.390 \\
\hline \multicolumn{7}{|l|}{ Vegetable consumption, $\%$} \\
\hline Hardly ever & 18.4 & 15.8 & 15.2 & 15.1 & 26.9 & 0.045 \\
\hline Once or twice per day & 72.3 & 73.8 & 72.7 & 73.3 & 62.7 & 0.190 \\
\hline Three times per day & 9.4 & 10.4 & 12.1 & 11.6 & 10.4 & 0.912 \\
\hline \multicolumn{7}{|l|}{ Fruit consumption, $\%$} \\
\hline Hardly ever & 8.6 & 8.8 & 10.9 & 10.3 & 14.9 & 0.327 \\
\hline 3 to 6 times per week & 65.6 & 60.0 & 59.4 & 60.3 & 64.9 & 0.562 \\
\hline Once or more per day & 25.8 & 31.3 & 29.7 & 29.5 & 20.1 & 0.174 \\
\hline \multicolumn{7}{|l|}{ Physical exercise, $\%$} \\
\hline Hardly ever & 44.9 & 41.7 & 43.6 & 46.6 & 58.2 & 0.035 \\
\hline Once per week & 37.1 & 42.9 & 41.2 & 41.8 & 32.8 & 0.309 \\
\hline Twice or more per week & 18.0 & 15.4 & 15.2 & 11.6 & 9.0 & 0.138 \\
\hline Salt intake (g/day of sodium chloride) & $11.6(3.4)$ & $11.2(3.4)$ & $11.1(3.3)$ & $11.2(3.1)$ & $11.3(3.4)$ & 0.532 \\
\hline Hours of sleep (h/night) & $6.5(0.8)$ & $6.6(0.8)$ & $6.5(0.8)$ & $6.4(0.7)$ & $6.0(0.8)$ & $<0.001$ \\
\hline Hours of single commutation (h) & $1.2(0.7)$ & $1.1(0.7)$ & $1.1(0.7)$ & $1.0(0.7)$ & $1.2(0.8)$ & 0.186 \\
\hline
\end{tabular}

^Unless otherwise indicated, values are expressed as the mean (standard deviations).

regression model and the slope of coefficient of this model was used. The slope for BMI was calculated similarly. Analysis of covariance was used to examine blood pressure slopes according to working hours per day adjusting for potential confounding factors. Multiple regression analysis was performed to examine an independent association of factors and their relative importance as determinants of blood pressure slopes. To examine possible interactions, the interactions of each covariate were tested by introducing product terms to models with the original variables, but no significant interactions were observed for interaction terms. In the statistical analyses, exact values were used for continuous variables. Dichotomised variables were coded as 1 for no potential risk factors and 2 for potential risk factors, and tripartited variables were graded from 1 to 3.

Data analysis was performed with the SPSS/PC statistical package (Marija J Norusis/ SPSS Inc, Chicago, IL, USA). All reported $p$ values are two tailed and $p<0.05$ was considered statistically significant.

\section{Results}

Table 1 shows the baseline characteristics of hypertension free subjects according to working hours per day. Mean age, SBP, MABP, $\mathrm{BMI}$, and hours of sleep and the percentages of those who were architects or research workers, were managers, ate vegetables hardly ever, and exercised hardly ever differed significantly by working hours per day. Participants who worked longer overtime were younger. The percentage of those who were architects or research workers tended to increase as working hours per day increased. On the other hand, the percentage of those who were managers decreased with an increase in working hours per day. Those who worked $\geqslant 10.0$ hours per day had lower SBP and MABP than those who worked < 10.0 hours per day. Those who worked 9.0-9.9 hours per day had the highest $\mathrm{BMI}$, and those who worked $<8.0$ hours per day had the second highest. The percentages of those who ate vegetables hardly ever and exercised hardly ever were highest among those who worked $\geqslant 11.0$ hours per day. Those who worked $\geqslant 11.0$ hours per day had the shortest hours of sleep. DBP, alcohol intake, cigarette smoking, eating breakfast, fruit consumption, salt intake, and hours of single commutation, did not differ significantly by working hours per day.

Table 2 shows the characteristics of hypertensive subjects according to working hours per day. Mean age, SBP, salt intake, and hours of sleep differed significantly by working hours per day. Hypertensives who worked longer overtime were younger. Those who worked $\geqslant$ 11.0 hours per day had the lowest SBP and the shortest hours of sleep, and those who worked $\geqslant 10.0$ hours per day had lower salt intake than those who worked $<10.0$ hours per day. The percentage of those who did not eat breakfast every morning did not differ significantly by working hours per day, but tended to increase with an increase in working hours per day.

Table 3 shows the association of working hours per day with the risk for development of hypertension during five years in hypertension free subjects. During five years of follow up representing 3940 person years, 336 men developed hypertension above the borderline level. The multivariate adjusted relative risk for hypertension above the borderline level, compared with those who worked $<8.0$ hours per day, was 0.91 (95\% confidence intervals (CI): 
Table 2 Characteristics of 418 hypertensive fapanese male office workers, according to working hours per day*

\begin{tabular}{|c|c|c|c|c|c|c|}
\hline \multirow[b]{2}{*}{ Characteristics } & \multicolumn{5}{|c|}{ Working hours per day } & \multirow[b]{2}{*}{$p$ value } \\
\hline & $\begin{array}{l}<8.0 \\
(n=111)\end{array}$ & $\begin{array}{l}8.0-8.9 \\
(n=123)\end{array}$ & $\begin{array}{l}9.0-9.9 \\
(n=84)\end{array}$ & $\begin{array}{l}10.0-10.9 \\
(n=45)\end{array}$ & $\begin{array}{l}\geqslant 11.0 \\
(n=55)\end{array}$ & \\
\hline Age $(y)$ & $47.4(4.3)$ & $47.2(4.3)$ & $46.4(4.9)$ & $45.4(5.4)$ & $44.6(6.1)$ & 0.002 \\
\hline \multicolumn{7}{|l|}{ Occupation, \% } \\
\hline Architect/research worker & 47.7 & 63.4 & 58.3 & 60.0 & 67.3 & 0.082 \\
\hline \multicolumn{7}{|l|}{ Position, \% } \\
\hline Manager & 55.9 & 56.9 & 54.8 & 46.7 & 50.9 & 0.779 \\
\hline \multicolumn{7}{|l|}{ Medication, \% } \\
\hline Hypertension & 18.9 & 17.1 & 21.4 & 26.7 & 21.8 & 0.699 \\
\hline Systolic blood pressure $(\mathrm{mm} \mathrm{Hg})$ & $146.2(11.4)$ & $146.5(12.7)$ & $150.2(13.4)$ & $148.4(11.2)$ & $143.8(10.3)$ & 0.028 \\
\hline Diastolic blood pressure $(\mathrm{mm} \mathrm{Hg})$ & $89.9(10.2)$ & $88.9(10.4)$ & $89.8(10.6)$ & $88.4(9.6)$ & $86.6(7.6)$ & 0.314 \\
\hline Mean arterial blood pressure ( $\mathrm{mm} \mathrm{Hg}$ ) & $108.6(9.0)$ & $108.1(9.1)$ & $109.9(9.9)$ & $108.4(6.7)$ & $105.7(6.7)$ & 0.090 \\
\hline Body mass index $\left(\mathrm{kg} / \mathrm{m}^{2}\right)$ & $24.6(1.3)$ & $24.3(3.4)$ & $24.3(3.1)$ & $23.8(3.2)$ & $24.0(2.4)$ & 0.536 \\
\hline Alcohol intake (g/day of ethanol) & $35.6(26.3)$ & $37.9(27.9)$ & $32.3(23.1)$ & $36.3(19.7)$ & $29.1(24.8)$ & 0.232 \\
\hline Smoking (cigarettes/day) & $12.3(16.2)$ & $14.7(16.3)$ & $12.7(17.6)$ & $11.1(13.0)$ & $13.4(14.7)$ & 0.711 \\
\hline \multicolumn{7}{|l|}{ Eating breakfast, \% } \\
\hline Not every morning & 9.9 & 19.5 & 19.0 & 22.2 & 27.3 & 0.065 \\
\hline \multicolumn{7}{|l|}{ Vegetable consumption, $\%$} \\
\hline Hardly ever & 18.0 & 18.7 & 15.5 & 8.9 & 18.2 & 0.620 \\
\hline Once or twice per day & 73.0 & 69.1 & 77.4 & 80.0 & 76.4 & 0.544 \\
\hline Three times per day & 9.0 & 12.2 & 7.1 & 11.1 & 5.5 & 0.587 \\
\hline \multicolumn{7}{|l|}{ Fruit consumption, \% } \\
\hline Hardly ever & 9.9 & 8.9 & 9.5 & 6.7 & 14.5 & 0.734 \\
\hline 3 to 6 times per week & 64.0 & 67.5 & 61.9 & 53.3 & 69.1 & 0.455 \\
\hline Once or more per day & 26.1 & 23.6 & 28.6 & 40.0 & 16.4 & 0.096 \\
\hline \multicolumn{7}{|l|}{ Physical exercise, \% } \\
\hline Hardly ever & 51.4 & 43.9 & 34.5 & 42.2 & 52.7 & 0.133 \\
\hline Once per week & 39.6 & 40.7 & 46.4 & 40.0 & 32.7 & 0.619 \\
\hline Twice or more per week & 9.0 & 15.4 & 19.0 & 17.8 & 14.5 & 0.336 \\
\hline Salt intake ( $\mathrm{g} /$ day of sodium chloride) & $11.7(3.1)$ & $11.9(2.9)$ & $11.5(2.7)$ & $10.2(3.2)$ & $10.7(3.2)$ & 0.007 \\
\hline Hours of sleep (h/night) & $6.6(0.7)$ & $6.6(0.8)$ & $6.6(0.7)$ & $6.5(0.6)$ & $6.0(0.8)$ & $<0.001$ \\
\hline Hours of single commutation (h) & $1.0(0.7)$ & $1.1(0.7)$ & $1.1(0.7)$ & $1.3(0.7)$ & $1.2(0.7)$ & 0.226 \\
\hline
\end{tabular}

^Unless otherwise indicated, values are expressed as the mean (standard deviations).

$0.69,1.21)$ for those who worked 8.0-8.9 hours per day, 0.79 (95\% CI: $0.57,1.08)$ for those who worked 9.0-9.9 hours per day, 0.63 (95\% CI: $0.43,0.91)$ for those who worked $10.0-10.9$ hours per day, and 0.48 (95\% CI: $0.31,0.74)$ for those who worked $\geqslant 11.0$ hours per day ( $\mathrm{p}$ for trend $<0.001$ ). As for the incidence of definite hypertension, 88 men developed definite hypertension during five years of follow up (representing 4531 person years). The respective multivariate adjusted relative risks for definite hypertension, compared with those who worked $<8.0$ hours per day, were 0.68 (95\% CI: $0.39,1.18), 0.93$

Table 3 Working hours per day and the risk of hypertension during five years of follow up in 941 hypertension free fapanese male office workers

\begin{tabular}{|c|c|c|c|c|c|c|}
\hline & \multicolumn{5}{|c|}{ Working hours per day } & \multirow[b]{2}{*}{$p$ for trend ${ }^{\star}$} \\
\hline & $<8.0$ & $8.0-8.9$ & $9.0-9.9$ & $10.0-10.9$ & $\geqslant 11.0$ & \\
\hline \multicolumn{7}{|l|}{ Hypertension above the borderline level } \\
\hline Cases & 113 & 92 & 61 & 41 & 29 & \\
\hline Person years & 1022 & 969 & 695 & 645 & 610 & \\
\hline Rate per 1000 person years & 110.6 & 94.9 & 87.8 & 63.6 & 47.6 & \\
\hline Age adjusted relative risk & $\begin{array}{l}1.00 \\
\text { (Reference) }\end{array}$ & 0.86 & 0.81 & $\begin{array}{l}0.60 \\
(0.42,087)\end{array}$ & 0.45 & $<0.001$ \\
\hline & (Reference) & $(0.66,1.14)$ & $(0.60,1.11)$ & $(0.42,0.87)$ & $(0.30,0.68)$ & \\
\hline $\begin{array}{l}\text { Multivariate adjusted relative risk† } \\
(95 \% \mathrm{CI})\end{array}$ & $\begin{array}{l}1.00 \\
\text { (Reference) }\end{array}$ & $\begin{array}{l}0.91 \\
(0.69,1.21)\end{array}$ & $\begin{array}{l}0.79 \\
(0.57,1.08)\end{array}$ & $\begin{array}{l}0.63 \\
(0.43,0.91)\end{array}$ & $\begin{array}{l}0.48 \\
(0.31,0.74)\end{array}$ & $<0.001$ \\
\hline \multicolumn{7}{|l|}{ Definite hypertension } \\
\hline Cases & 31 & 23 & 20 & 10 & 4 & \\
\hline Person years & 1221 & 1160 & 782 & 711 & 658 & \\
\hline Rate per 1000 person years & 25.4 & 19.8 & 25.6 & 14.1 & 6.1 & \\
\hline $\begin{array}{l}\text { Age adjusted relative risk } \\
(95 \% \mathrm{CI})\end{array}$ & $\begin{array}{l}1.00 \\
\text { (Reference) }\end{array}$ & $\begin{array}{l}0.78 \\
(0.45,1.34)\end{array}$ & $\begin{array}{l}1.03 \\
(0.58,1.81)\end{array}$ & $\begin{array}{l}0.57 \\
(0.28,1.18)\end{array}$ & $\begin{array}{l}0.25 \\
(0.09,0.70)\end{array}$ & 0.010 \\
\hline $\begin{array}{l}\text { Multivariate adjusted relative risk† } \\
(95 \% \mathrm{CI})\end{array}$ & $\begin{array}{l}1.00 \\
\text { (Reference) }\end{array}$ & $\begin{array}{l}0.68 \\
(0.39,1.18)\end{array}$ & $\begin{array}{l}0.93 \\
(0.53,1.65)\end{array}$ & $\begin{array}{l}0.56 \\
(0.27,1.17)\end{array}$ & $\begin{array}{l}0.33 \\
(0.11,0.95)\end{array}$ & 0.045 \\
\hline
\end{tabular}

${ }^{\star}$ The test for trend is calculated across increasing categories of working hours per day. +Controls for age, occupation, position, mean arterial blood pressure, body mass index, alcohol intake, cigarette smoking, eating breakfast, vegetable consumption, fruit consumption, regular physical exercise, salt intake, hours of sleep, and hours of commutation at baseline.

Table 4 Multivariate adjusted slope of blood pressure during five years of follow up according to working hours per day in 847 hypertension free fapanese male office workers

\begin{tabular}{lllllll}
\hline \multicolumn{7}{l}{ Working hours per day } \\
\cline { 2 - 6 } & $\begin{array}{l}<8.0 \\
(n=232)\end{array}$ & $\begin{array}{l}8.0-8.9 \\
(n=216)\end{array}$ & $\begin{array}{l}9.0-9.9 \\
(n=146)\end{array}$ & $\begin{array}{l}10.0-10.9 \\
(n=130)\end{array}$ & $\begin{array}{l}\geqslant 11.0 \\
(n=123)\end{array}$ & $p$ value \\
\hline Systolic blood pressure (mm Hg/year) & 1.25 & 1.17 & 0.96 & 0.73 & 0.90 & 0.160 \\
Diastolic blood pressure (mm Hg/year) & 1.52 & 1.49 & $\begin{array}{l}1.55 \\
1.34\end{array}$ & 1.18 & 1.05 & 0.021 \\
Mean arterial blood pressure (mm Hg/year) & 1.43 & 1.38 & 1.04 & 1.01 & 0.043 \\
\hline
\end{tabular}

${ }^{\star}$ Controls for age, occupation, position, each blood pressure, body mass index, alcohol intake, cigarette smoking, eating breakfast, vegetable consumption, fruit consumption, regular physical exercise, salt intake, hours of sleep, and hours of commutation at baseline and slope of body mass index. 
Table 5 Stepwise regression analyses for slopes of blood pressure during five years of follow up in 847 hypertension free fapanese male office workers

\begin{tabular}{|c|c|c|c|c|c|c|}
\hline Variables & $\begin{array}{l}\text { Regression } \\
\text { coefficient }\end{array}$ & $\begin{array}{l}\text { Standard } \\
\text { error }\end{array}$ & $\begin{array}{l}\text { Standardised } \\
\text { regression coefficient }\end{array}$ & tvalue & p value & Cumulative $r^{2}$ \\
\hline \multicolumn{7}{|l|}{ Slope of systolic blood pressure (mm $\mathrm{Hg} /$ year) } \\
\hline Systolic blood pressure ( $\mathrm{mm} \mathrm{Hg}$ ) & -0.083 & 0.007 & -0.389 & -12.16 & $<0.001$ & 0.133 \\
\hline Alcohol intake (g/day of ethanol) & 0.012 & 0.003 & 0.133 & 4.18 & $<0.001$ & 0.151 \\
\hline Working hours (h/day) & -0.085 & 0.038 & -0.074 & -2.25 & 0.025 & 0.159 \\
\hline Slope of body mass index $\left(\mathrm{kg} / \mathrm{m}^{2} /\right.$ year $)$ & 0.972 & 0.333 & 0.093 & 2.92 & 0.004 & 0.166 \\
\hline Age $(y)$ & 0.033 & 0.014 & 0.078 & 2.40 & 0.017 & 0.171 \\
\hline \multicolumn{7}{|l|}{ Slope of diastolic blood pressure (mm Hg/year) } \\
\hline Diastolic blood pressure ( $\mathrm{mm} \mathrm{Hg}$ ) & -0.085 & 0.006 & -0.413 & -13.18 & $<0.001$ & 0.162 \\
\hline Slope of body mass index $\left(\mathrm{kg} / \mathrm{m}^{2} /\right.$ year $)$ & 0.995 & 0.251 & 0.123 & 3.96 & $<0.001$ & 0.174 \\
\hline Working hours (h/day) & -0.079 & 0.028 & -0.089 & -2.82 & 0.005 & 0.185 \\
\hline Occupation: architect/research worker & -0.249 & 0.119 & -0.070 & -2.10 & 0.026 & 0.190 \\
\hline Alcohol intake ( $\mathrm{g} /$ day of ethanol) & 0.005 & 0.002 & 0.068 & 2.16 & 0.031 & 0.195 \\
\hline \multicolumn{7}{|c|}{ Slope of mean arterial blood pressure ( $\mathrm{mm} \mathrm{Hg} /$ year) } \\
\hline Mean arterial blood pressure ( $\mathrm{mm} \mathrm{Hg}$ ) & -0.074 & 0.007 & -0.359 & -11.13 & $<0.001$ & 0.116 \\
\hline Slope of body mass index $\left(\mathrm{kg} / \mathrm{m}^{2} /\right.$ year $)$ & 0.979 & 0.253 & 0.123 & 3.86 & $<0.001$ & 0.129 \\
\hline Working hours (h/day) & -0.081 & 0.028 & -0.093 & -2.88 & 0.004 & 0.140 \\
\hline Alcohol intake ( $\mathrm{g} /$ day of ethanol) & 0.007 & 0.002 & 0.098 & 3.03 & 0.003 & 0.150 \\
\hline Occupation: architect/research worker & -0.251 & 0.113 & -0.072 & -2.23 & 0.026 & 0.155 \\
\hline
\end{tabular}

Percentage of variation accounted for $=r^{2} \times 100 . r$ : multiple correlation. Variables included in the multiple regression analyses were age, occupation, position, working hours, body mass index, alcohol intake, cigarette smoking, eating breakfast, vegetable consumption, fruit consumption, regular physical exercise, salt intake, hours of sleep, and hours of commutation at baseline and slope of body mass index.

(95\% CI: $0.53,1.65), 0.56$ (95\% CI: 0.27 , 1.17 ), and $0.33(95 \% \mathrm{CI}: 0.11,0.95)$ ( $\mathrm{p}$ for trend $=0.045$ ).

Table 4 shows the slopes of SBP, DBP, and MABP during five years according to working hours per day in hypertension free subjects. Consecutive six values of blood pressure were available for 857 men (91.7\%). Ten men who started taking medication for hypertension during the observation period were excluded and the study population for analyses of slopes of blood pressure consisted of 847 men. The multivariate adjusted slopes of DBP and MABP differed significantly by working hours per day, and the slopes of DBP and MABP decreased as working hours per day increased.

Table 5 shows the results of multiple linear regression analyses for slopes of blood pressure during five years in hypertension free subjects. Independent and significant correlates with slopes of SBP, DBP, and MABP were, in the order of relative importance: SBP (negative), alcohol intake, working hours (negative), slope of BMI, and age for the slope of SBP; DBP (negative), slope of BMI, working hours (negative), occupation of architect or research worker (negative), and alcohol intake for the slope of DBP; and MABP (negative), slope of BMI, working hours (negative), alcohol intake, and occupation of architect or research worker (negative) for the slope of MABP. The cumulative percentages of variation for the slopes of SBP, DBP, and MABP were $17.1 \%, 19.5 \%$, and $15.5 \%$, respectively.

\section{Discussion}

Although long working hours or overtime has received an increasing attention for its adverse effects of health, ${ }^{18}$ evidence linking long working hours to the risk for hypertension is very limited. Hayashi et $a l^{19}$ reported that for male white collar workers with normal blood pressure and those with mild hypertension, the 24 hour average blood pressure of the overtime groups was higher than that of the control groups and that for those who periodically did overtime work, the 24 hour average blood pressure during the busy period increased. On the other hand, data collected in the Minnesota Heart Survey did not find any association between job experiences including working hours and blood pressure. ${ }^{20}$ As for the association between job strain or stress and blood pressure, Schwartz et $a^{21}$ reported that psychological job strain was related to mean awake ambulatory blood pressure, cross sectionally and longitudinally, in male employees and that the estimated effect on SBP of always (versus never) having high job strain exceeded the predicted effects of a difference of $40 \mathrm{lb}$ in weight or 20 years in age. Lindquist et $a l^{2}$ reported in a study of workers in a government tax office that work stress in itself had no direct effect on blood pressure, but the ways that people reported coping with stress were significantly related to blood pressure, with blood pressure elevation effects appearing to be mediated largely by maladaptive or unhealthy coping behaviours such as excessive consumption (food, cigarettes, and alcohol) and physical inactivity. These inconclusive results may have resulted in part from lifestyle differences in the study populations but also may have been strongly influenced by different perception of overwork or stress.

In this study, we found that working long hours was an independent negative factor associated with development of hypertension above the borderline level and definite hypertension, controlling for potential predictors of hypertension. Furthermore, the slopes of blood pressure over five years decreased as working hours per day increased, and working hours were independently negatively associated with the slopes of blood pressure. These results suggest that long working hours are negatively associated with the risk for hypertension in Japanese male white collar workers.

The contribution of long overtime to the lower risk for hypertension is uncertain. In this study, architects or research workers worked longer overtime than clerks and being an architect or a research worker (versus being a clerk) was negatively associated with the slope of 
blood pressure. These results may indicate that the influence of work type is important for determining the perception of overwork or stress and its associated responses of blood pressure. As architects or research workers who work longer overtime might be especially competitive, or may particularly enjoy their work, they may not feel working long overtime as job strain or stress. ${ }^{23}$ In this population, to quantify the physical activity of participants, their major physical activities were recorded every 15 minute during a day and the 24 hour energy expenditure was calculated. ${ }^{24} 25$ The 24 hour energy expenditure values differed significantly ( $\mathrm{p}<0.001$, analysis of variance) by working hours per day. The 24 hour energy expenditure was $2331 \mathrm{kcal} /$ day (SD 274) for those who worked $<8.0$ hours per day, $2414 \mathrm{kcal} /$ day (SD 275) for those who worked 8.0-8.9 hours per day, $2476 \mathrm{kcal} /$ day (SD 273) for those who worked 9.0-9.9 hours per day, $2560 \mathrm{kcal} /$ day (SD 281) for those who worked 10.0-10.9 hours per day, and $2586 \mathrm{kcal} /$ day (SD 269) for those who worked $\geqslant 11.0$ hours per day. Although this is of course unlikely to explain fully the decreased risk seen in those who worked longer overtime, the negative association of working hours with risk for hypertension might be derived from the high energy expenditure related to long working hours or increased physical activity. However, men who worked $\geqslant 11$ hours per day showed maladaptive lifestyle factors such as less frequencies of vegetable consumption and physical exercise and less hours of sleep. Strategies for nonpharmacological management and prevention of hypertension should take greater account of coping mechanisms that underlie multifarious lifestyle factors. Further research is needed to establish whether long overtime affects the risk for hypertension independently or is bad for health. ${ }^{26}$

There are several limitations to this study. One is that we assessed participants' working hours by their subjective reporting. However, because a questionnaire used in this study was confidential and data on daily working hours were only used for health management, over or underreporting their daily working hours is unlikely to have occurred.

The second limitation is that working hours during the follow up were not included. Spearman's rank correlation coefficient was 0.652 (p $<0.001$ ) for working hours per day between at baseline and at the end of follow up among 847 subjects who could be followed up until the end of observation. This indicates that those who worked longer overtime at entry tended to do so during the follow up period. The observed associations between working hours at baseline and the decreased risk for hypertension may reflect the effects of long working hours over a five year observation period. As for blood pressures by working hours per day at the end of follow up, the changes in SBP and DBP between at baseline and at the end of follow up did not differ significantly by working hours per day at the end of follow up. However, mean SBP and DBP at the end of follow up differed significantly by working hours per day
KEY POINTS

- The effect of long overtime on the risk for hypertension is not certain.

- This study reports for the first time the association of working long hours with the risk for development of hypertension at the work site.

- The risk for development of hypertension during five years of follow up was lower among those who worked longer overtime.

- Working hours were negatively associated with the slopes of blood pressure during the follow up.

- These results indicate that working long overtime may not contribute to the development of hypertension.

at the end of follow up ( $p=0.030$ and $p=$ 0.016 , respectively), and those who worked $\geqslant$ 10.0 hours per day had lower SBP and DBP than those who worked < 10.0 hours per day: $128.1 \mathrm{~mm} \mathrm{Hg}$ (SD 13.1) and $80.4 \mathrm{~mm} \mathrm{Hg}$ (SD 9.1) for those who worked $<8.0$ hours per day; $128.5 \mathrm{~mm} \mathrm{Hg}$ (SD 12.0) and 80.2 $\mathrm{mm} \mathrm{Hg}$ (SD 9.3) for those who worked 8.0-8.9 hours per day; $126.9 \mathrm{~mm} \mathrm{Hg}$ (SD 11.9) and $81.0 \mathrm{~mm} \mathrm{Hg}$ (SD 9.1) for those who worked 9.0-9.9 hours per day; $124.9 \mathrm{~mm} \mathrm{Hg}$ (SD 12.0) and $78.2 \mathrm{~mm}$ $\mathrm{Hg}$ (SD 9.8) for those who worked 10.0-10.9 hours per day; and $125.4 \mathrm{~mm} \mathrm{Hg}$ (SD 11.8) and $78.0 \mathrm{~mm} \mathrm{Hg}$ (SD 9.1) for those who worked $\geqslant 11.0$ hours per day, respectively. As for blood pressures by position, mean SBP and DBP at baseline and the changes in SBP and DBP between at baseline and at the end of follow up did not differ significantly between participants who became a manager and who did not during the follow up period. These results indicate that working long hours at the end of follow up and a rise in rank during the follow up period may not contribute to the increase in blood pressure in Japanese male white collar workers. However, we did not assess participants' health related behaviours and dietary habits during the follow up period. As alcohol and salt use, fruit and vegetable consumption, and physical activity have important influences on the blood pressure and the prevalence of hypertension, ${ }^{27-31}$ health related behaviours and dietary habits during the follow up period may be associated with risk for hypertension. Further researches should be needed to clarify the causal association between working hours and risk for hypertension.

The third limitation is that in this study, we could not evaluate job strain, job stressors or social support at work. ${ }^{32-34}$ However, the percentages of men with subjective symptoms such as headache, ear noises, general fatigue, loss of appetite, loss of sleep, dizziness, constipation, fatigue of the eyes, and stiff shoulders did not differ significantly among the five groups according to working hours per day. These results suggest that long overtime did not strongly affect subjective symptoms and might be unlikely to induce job stress in this population. 
The final limitation is that the normotensive cohort in this study, particularly in older age groups may not be typical of the general population. People whose blood pressure was already increased beyond the borderline level when they were younger or who reported taking drugs for or a past history of hypertension during the initial examination were excluded from this survey. Thus, the selection of men with rigorously normal blood pressure level at study entry might possibly affect the findings.

Despite these potential limitations, our findings, obtained from a cohort of Japanese male white collar workers, indicate that working longer overtime is associated with the lower risk for hypertension. However, it is undoubtedly sufficient to raise the concern that long working hours are associated with the risk of significant health outcomes, including cardiovascular disease. Much remains to be explored in term of the nature of the factors involved.

We would like to express our appreciation of all the employees and the Medical Office of the Osaka Main Office of Takenaka Corporation for their valuable cooperation for this study. We are also grateful to Ryuichi Kaneko and his colleagues at the Japan Labour and Welfare Association for collecting and coding the data accurately and consistently over a period of five years.

Funding: this study was supported in part by Grand in Aid for the prevention of lifestyle related diseases from the Arteriosclerosis Prevention Association, Tokyo, Japan.

Conflicts of interest: none.

1 Ono Y, Watanabe S, Kaneko S, et al. Working hours and fatigue of Japanese flight attendants (FA). $\mathcal{f}$ Hum Ergol (Tokyo) 1991;20:155-64.

2 Proctor SP, White RF, Robins TG, et al. Effect of overtime work on cognitive function in automotive workers. Scand $\mathcal{f}$ Work Environ Health 1996;22:124-32.

3 Waersted $\mathrm{M}$, Westgaard RH. Working hours as a risk factor in the development of musculoskeletal complaints. Ergoin the development of
nomics 1991;34:265-76.

4 Cooper CL, Davidson MJ, Robinson P. Stress in the police service. f Occup Med 1982;24:30-6.

5 Richardsen AM, Burke RJ. Occupational strss and job satisfaction among physicians: sex difference. Soc Sci Med 1991;33:1179-87.

6 Cooper CL, Roden J. Mental health and satisfaction among tax officers. Soc Sci Med 1985;21:747-51.

7 Hurrel JJ, Lindström K. Comparison of job demands, control and psychosomatic complaints at different career
stages of managers in Finland and the United States. Scand $\mathcal{f}$ Work Environ Health 1992;18 (suppl 2):S11-13.

8 Watanabe S, Torii J, Shinkai S, et al. Relationships between health status and working conditions and personalities among VDT workers. Environ Res 1993;61:258-65.

9 Russek HI, Zohnman BL. Relative significance of heredity, diet and occupational stress in CHD of young adults. $A m \mathscr{f}$ Med Sci 1958;235:266-75.

10 Buell P, Breslow L. Mortality from coronary heart disease in California men who work long hours. I Chronic Dis 1960;11:615-26.
11 Uehata T. Long working hours and occupational stressrelated cardiovascular attacks among middle-aged workers in Japan. F Hum Ergol (Tokyo) 1991;20:147-53.

12 Kageyama T, Nishikido N, Kobayashi, et al. Commuting, overtime, and cardiac autonomic activity in Tokyo. Lancet 1997;350:639.

13 Rissler A. Stress reactions at work and after work during a period of quantitative overload. Ergonomics 1978;20:13-16.

14 Watson RD, Hamilton CA, Reid JL, et al. Changes in plasma norepinephrine, blood pressure and heart rate during physical activity in hypertensive man. Hypertension 1979;1: 341-6.

15 WHO Expert Committee. Arterial Hypertension. WHO Technical Report 628. Geneva: WHO, 1978

16 Date C, Yamaguchi M, Tanaka H. Development of a food frequency questionnaire in Japan. I Epidemiol 1996:6 (suppl 3):S131-6.

17 Cox DR. Regression models and life-tables. Fournal of the Royal Statistical Society. Series B, Methodological 1972;34: 187-202.

18 Spurgeon A, Harrington JM, Cooper CL. Health and safety problems associated with long working hours: a review of the current position. Occup Environ Med 1997;54:367-75.

19 Hayashi T, Kobayashi Y, Yamaoka K, et al. Effect of overtime work on 24 -hour ambulatory blood pressure. 7 Occup Environ Med 1996;38:1007-11.

20 Sorensen G, Pirie P, Folsom A, et al. Sex differences in the relationship between work and health: the Minnesota Heart Survey. F Health Soc Behav 1985;26:379-94.

21 Schwartz JE, Schnall PL, Pickering TG. The effect of job strain on ambulatory blood pressure in men over 6 years is comparable to other risk factors. [Abstract]. Glasgow: International Society for Hypertension, 1996

22 Lindquist TL, Beilin LJ, Knuiman MW. Influence of lifestyle, coping, and job stress on blood pressure in men and women. Hypertension 1997;29:1-7.

23 Bliese PD, Halverson RR. Individual, nomothetic models of job stress. An examination of work hours, cohesion and well-being. Fournal of Applied Social Psychology 1996;26: 1171-81.

24 Bouchard C, Tremblay A, Leblanc C, et al. A method to assess energy expenditure in children and adults. Am f Clin Nutr 1983;37:461-7.

25 Health Promotion and Nutrition Division, Health Service Bureau, Ministiry of Health and Welfare. Recommended dietary allowance for the fapanese. [In Japanese]. 4th revision. Tokyo: Dai-Ichi Shuppan, 1989.

26 Harrington JM. Working long hours and health. BMF 1994; 308:1581-2.

27 Kromhout D, Bosschieter EB, Coulander CL. Potassium, calcium, alcohol intake and blood pressure: the Zutphen Study. Am f Clin Nutr 1985;41:1299-304.

28 Friedman GD, Selby JV, Quesenberry CP Jr, et al. Precursors of essential hypertension: body weight, alcohol and salt use, and parental history of hypertension. Prev Med 1988;17:387-402.

29 Stamler R. Implications of the INTERSALT study. Hypertension 1991;17 (suppl 1):16-20.

30 Langford HG. Dietary potassium and hypertension: epidemiologic data. Ann Intern Med 1983;98:770-2.

31 Hayashi T, Tsumura K, Suematsu C, et al. Walking to work and the risk for hypertension in men: the Osaka Health Survey. Ann Intern Med 1999;131:21-6.

32 Netterstrom B, Kristensen TS, Damsgaard MT, et al. Job strain and cardiovascular risk factors: a cross sectional study of employed Danish men and women. Br F Ind Med 1991;48:684-9.

33 Kawakami N, Haratani T. Epidemiology of job stress and health in Japan: review of current evidence and future direction. Ind Health 1999;37:174-86.

34 Johnson JV, Hall EM. Job strain, work place social support, and cardiovascular desease: a cross-sectional study of a random sample of the Swedish working population. $A m \mathcal{F}$ Public Health 1988;78:1336-42. 